\title{
Research on Teaching Reform and Exquisite Course Construction of Landscape Ecology
}

\author{
Lin Li \\ Department of Environmental Art Design, Hebei Institute of Fine Art ,ShiJiaZhuang HeBei, 050700, \\ China
}

Keywords: Landscape Ecology, Exquisite course, Discipline construction, Teaching reform

\begin{abstract}
Based on the course characteristics and the development of landscape ecology pattern, this paper analyses the problems in current development of landscape ecology such like discipline characteristic is not obvious, teaching material is not standard, practice is weak, lack of teaching resources and so on, from integration about horizontal and vertical to explore the subject architecture and landscape ecology construction, putting forward idea about teaching reform and construction from the discipline construction of knowledge system, practice teaching contents reform and teaching method of fusion.
\end{abstract}

\section{Introduction}

Landscape Ecology is a rapid development and effective widely emerging discipline, it derives from geography in the cross of ecology, landscape science and biology of the geography of geographic spatial interaction cross-sectional study of ecosystem function and ecology of longitudinal study of interaction in one, the landscape as the object, through the energy flow, material flow and information flow and value stream flows, species on the earth's surface in the exchange, study the landscape spatial structure, internal function and the relationship between time and space and space-time model. Fully reflects the current Landscape Ecology environmental protection and the sustainable development of human era theme, is to recognize and solve human resources, environment and other major issues in an effective way, has very wide application and development prospect in the protection of biological diversity, use of land and management of regional, changing of global.

\section{Characteristics and Development Pattern of Landscape Ecology}

Course characteristic of Landscape Ecology. Landscape Ecology has two main features: a. close cross and integration. Landscape Ecology is an emerging interdisciplinary field of ecology and geography, is also a bridge that crosses from the various disciplines, involving multiple natural and humanistic sciences, meeting the diverse needs of the different background of professional. In 1999, international landscape ecological society (IALE) located it between the natural sciences and humanities on the constitution revision. Therefore, Landscape Ecology not only can be used to guide landscape planning and management, development and utilization of resources, biodiversity conservation, etc, can also serve the social scientists and policymakers, it is a course with extremely strong overlapping and fusion. b. strong practicability and practicality. The basic concept, theory, principle of Landscape Ecology, have been widely applied in the territorial control, resource development, land use, natural protection, regional planning, Tourism development, etc., at the same time, research of the Landscape Ecology begin to pay a close attention to realistic problems, such as optimizing effect of landscape, standardizing activity of human beings, and improve the living environment of human being, etc, [1]making the Landscape Ecology a important means to solve many social and environmental problems. 
The curriculum development pattern of Landscape Ecology. Currently, in Chinese colleges and universities, Landscape Ecology has become required or elective courses of many major ,like agriculture, environmental ecology, land resource management, geographical science, landscape architecture, landscape planning and tourism management, and other related professional, cultivating a large number of applied talents on work to protect the land resources management, the natural environment and planning, tourism development and ecological assessment, urban planning and landscape architecture. In summing up the setting of curriculum for Landscape Ecology in China, it mainly has the following several kinds of development model.

Intersect of Geography and Land Resources. Relying on the basic concepts of Landscape Ecology, the basic theory and research methods, absorbing the essence of geographical science, making landscape as the research object, the landscape spatial pattern, function and the relationships between research and time variation of lateral changes and the longitudinal study, the combination of landscape pattern optimization configuration and planning through the teaching emphasis to master basic concept and basic principle of Landscape Ecology, landscape structure change of driving factors analysis of landscape ecological planning and design of the practical application, Landscape Ecology and the relationship between sustainable land use, etc., [2]in geography, resources and environment, for the future work in the field of land planning, etc. Such as Beijing normal university, land resource management specialty and geographical sciences, Fujian normal university geography education specialty and land planning, resources and environment of Fujian agriculture and forestry university and the urban and rural planning management and so on.

Intersect of Agriculture, Forestry and Environmental Studies. Landscape Ecology as a effective discipline on solution to the current resources and environment, the problems of the biodiversity protection in the development and utilization of resources, urban development planning, land use planning and environmental protection plays an important role, with the research methods of Landscape Ecology, such as composite population theory, seepage theory and scale theory, fragmentation geometry theory and the relationship between landscape process and landscape function is a good way to explain all phenomena of the landscape on different scales, and the key to find the problem, in order to establish the sustainable development of agriculture, forestry mode for reference, and in the service of environmental assessment, environmental protection and reasonable and effective utilization of resources, and many other aspects. Such as AnHui normal university of agriculture and the environment ecology of ecological engineering, GuangXi university, Central University for nationalities ecology specialty, FuJian agriculture and forestry university of forestry and ecology.

Intersect of Landscape Architecture and Landscape Planning. Landscape Ecology belongs to the category of spatial ecology, which is studying the composite law of ecological systems in space, becoming the important theoretical support of landscape planning and design. Through the study of Landscape Ecology can make students to master relevant knowledge and theory, on the basis of cultivating ecological consciousness and the concept of sustainable development of landscape planning and design talent, the master of landscape classification, space combination, methods of optimal allocation, cultivate professionalism in urban and rural landscape planning, landscape architecture, landscape engineering design and other aspects. Such as landscape architecture of TongJi university and landscape planning and tourism management specialty of landscape architecture of YunNan university, agriculture, forestry and landscape engineering specialty and garden planning and design of ZheJiang university, etc.

Intersect of Biological Sciences and Biotechnology Subject. To landscape as a basic scale, research on the landscape spatial pattern, the structure and function change and migration, the 
relationship between the material flow and energy circulation. Landscape pattern changes tend to affect the all kinds of ecological process, such as regional microclimate, soil nutrient flow and erosion, biological migration, soil erosion, etc. [3] therefore, through the study of Landscape Ecology will provide biological science and biological technology subject with new theory and method, to seek better biological conservation. Such as BeiJing Normal University, biotechnology and biological sciences in college of life science.

Intersect of Management, Tourism and other Disciplines. Landscape Ecology plays an important position in ecological protection and recreation resource management, students majoring in planning management resources and environment and urban and rural planning and management, tourism management can master the Landscape Ecology in landscape planning, land use, the application of tourism development, etc through learning, make its ideas and methods in study of landscape scale and public management (design, planning, decision-making) subject unifies, to solve practical problems, and make decisions. Such as the resources and environment of FuJian Agriculture and Forestry University and the urban and rural planning management and forest resources protection and recreation of professional in GuiZhou University, management of tourism scenic spot of ZheJiang Forestry University and professional tourism management of TongJi university, etc.

\section{The Problems Faced by Course Construction and Teaching Reform of Landscape Ecology}

In recent years, rapid progress in the development of Landscape Ecology, scientific research emerge in endlessly, applications continue to expand, challenging the current relatively fixed teaching pattern of Landscape Ecology, in both the course construction and teaching reform, there are many problems to be solved.

Positioning is not Clear, Features is not Prominent. Landscape Ecology is rooted in different research tradition and method in the fertile soil of many subjects, given the strong vitality of Landscape Ecology, at the same time also will face a strong crisis of differentiation . a. positioning is not clear in professional training. while the Landscape Ecology was set up in many professional training in comprehensive universities, normal universities and colleges of agriculture and forestry, but many for the professional course, elective courses and professional direction less for professional core courses in the specialized course. In addition, in the actual teaching, various colleges and universities often fragmented, the Landscape Ecology course mechanically added in various professional training plan, make the discipline and connecting with professional Settings in other subjects is poorer, lead to some students learning enthusiasm is not high, with the implicit sexual passivity, its position does not highlight in the development of discipline [4]. At present, the Landscape Ecology position is not clear in the professional training, not only in subject position in the development of a lack of continuity, is in a state of passivity and dependency, discipline characteristic is not prominent.

The Teaching Material is without Specification, Lack of Fine Materials. In 1996, Xu Huacheng wrote the first "Landscape Ecology" of the teaching material of our country. Then, Du-ning Xiao, Zhi-xiang Zhou, Xin-xiao Yu, Jian-guo Wu, Bo-jie Fu, Jin-pin Guo, Hui-qing Liu, Mao-song Liu also has written the teaching materials of "Landscape Ecology" for graduate and undergraduate. Although these different versions of the teaching materials reflect the current diversification of Landscape Ecology, suggestting that the Landscape Ecology present the phenomenon of flourishing with each passing day, but also from the other side which shows on the Landscape Ecology in the textbook is still insufficient standard, lack of high-quality goods or classical teaching material, the intersection of different disciplines and makes the Landscape 
Ecology wide monarch channels, constantly absorbing the latest theoretical results of relevant disciplines (domain), with relatively fixed teaching materials in different ways. Different professionals have a low flexibility of selection in teaching materials, excellent teaching material is very few. It is known that landscape architecture and planning management professional choose teaching materials generally written by $\mathrm{Bo}$-jie $\mathrm{Fu}$ in 2002, write the principle and application of Landscape Ecology; Land resources management major and geographical science major mainly choose the landscape ecological pattern written by jian-guo wu in 2007, process, scale and level. Colleges and universities of agriculture and ecological environment of agriculture and forestry teaching mainly choose $\mathrm{Xu}$ Huacheng or guo $\mathrm{j} \mathrm{p}$ of the Landscape Ecology, also some school began to use foreign teaching materials, such as Landscape Ecologyin Theoryand Practice written by Turner,etc. [5] The characteristics of these materials is that the theoretical is strong,the systematic is fine, but often the maneuverability is low, testable is weak, it cannot meet the development of subject neither the demand of different background of professional.

Paying too much Attention on Theoretical Teaching, too Little on Practice Teaching. At present, in the study of Landscape Ecology, the integrated use of wild positioning observation method, experimental simulation, remote sensing technology and model have been closely watched, however, in the process of practical teaching of Landscape Ecology, because the students' foundation is weak, teaching resources are limited, professional background and experience is not enough, some unreasonable curriculum practice teaching link of many factors, such as Landscape Ecology is relatively weak.

The settings of practice teaching of Landscape Ecology is unreasonable. At present, all kinds of colleges and universities require this course credits in 2.0-3.0 credits, the total class hours in 50 hours or so, but the practice class accounts for a small proportion of the total teaching hours, some schools even do not arrange teaching practice. Practice teaching instruction is insufficient or standard. At present, the teaching practice instructions of the course written by the colleges themselves, without no strict requirement and outline of the rules-based standards, practice teaching content is different, which ,to a certain extent, affect the quality and effect of teaching practice. c. the problem of base construction of practice is more prominent. on the one hand, there is no system of practice base and monitoring platform, the process of internship is often tour, tasted, On the other hand, lack of the experimental equipment for forming a complete set, which is difficult to meet the needs of students on field investigation and laboratory experiments.

The Teachers Troop is young, Teaching Resources is Nervous. The rising and development of a discipline, there must be a strong teaching staff and a series of a complete set of perfect teaching facilities as a strong backing, otherwise no matter or in the course teaching in teacher training and so on all will be faded, the phenomenon of empty and abstract. In China, the research on Landscape Ecology are concentrated in a few, and some research institutions, the landscape ecology has not yet been established throughout the country with a network talents, research institutions, personnel training, has not yet formed a certain scale of Landscape Ecology research team . Make the agriculture and forestry university of Fujian forestry college as an example, the Landscape Ecology oriented teachers and teaching resources are limited, on the one hand, performance in the opening of the contradiction of the new professional and enrollment expansion between the lack of teachers. On the other hand, the Infrastructure of teaching condition is relatively backward, less quantity of lab instrument and apparatus, slow update speed, teaching resources are nervous. 


\section{The Thinking and Countermeasures of Curriculum Construction and Teaching Reform of Landscape Ecology}

In extensive reference to domestic and foreign many colleges and universities teaching reform pattern, on the basis of combination of forestry college of FuJian agriculture and forestry university Landscape Ecology construction course, on how to strengthen the course construction of Landscape Ecology, innovation of teaching content reform and teaching practice, aiming at building a vibrant, rich content, the diversification of teaching means, commonness and personality unity and operability on teaching mode of the Landscape Ecology, to promote quality education and the cultivation of innovative talents.

The Thinking and Countermeasures of Curriculum Construction of Landscape Ecology. Horizontal integration. Fine construction of course platform, strengthen the horizontal cooperation so as to realize the sharing of teaching resources, therefore, put forward the following Suggestions: (1)Build academic exchange platform. Through the network teaching, the open lectures, academic seminar as well as employment form such as excellent teachers to promote the construction discipline platform of Landscape Ecology. (2)Strengthen contact between intercollegiate, strengthen the relationship between schools and enterprises and units. Suggested teachers between the different colleges and universities exchange swaps ", "exchange form such as interns, Shared scientific research subject, strengthen students in the related enterprises and units acquisition of guidance, etc., it can not only realize practice content and method of draw lessons from each other, but also deepen the teaching links with the production practice, kill two birds with one stone of it. (3) Establish an open teaching mode.

Suggest that teachers' scientific research subject and research projects open to undergraduates, actively organize students to declare the Landscape Ecology research direction of national and provincial college students innovation experiment program, the undergraduate students to participate in related research topics of Landscape Ecology. In our hospital, for instance, by taking the Landscape Ecology of the national natural science fund project, key project of department of Fujian province, Fujian province natural science fund projects open to all students, not only promote the enthusiasm and initiative of the students on the course, but also for our Landscape Ecology construction and provide strong technical support and practice cradle.

The Longitudinal Ascension. According to characteristics of landscape ecological course, helps improve teaching level from four aspects: (1)Deepen and expand the teaching field, the understanding of the landscape. Landscape has the "landscape", "Mosaic" natural, "heterogeneity" mosaics and other means, landscape aesthetics, geography and ecology of fields, such as the research object, and become the important subject of the foundations of modern Landscape Ecology, therefore, choose the appropriate landscape, deepen the impression landscape character, is very important to students' learning and understanding of Landscape Ecology. (2) To set up the deep Landscape Ecology research direction. In the discipline construction of Landscape Ecology, not only in the undergraduate teaching links (including graduation thesis, graduation design) to set up the research direction of Landscape Ecology, more want to set up in the master's and doctoral education research direction of Landscape Ecology, by setting up the Landscape Ecology, Dr Research direction to enrich the connotation of Landscape Ecology, and realizing the extent of the teaching of cohesion. (3) Strengthen the longitudinal development in the practice field. Should not only emphasize the combination of "learning" and "study", namely according to different students to set up the Landscape Ecology research, through scientific research, national and provincial scientific research project, college students' innovative projects, all kinds of landscape planning 
projects, etc.) Promote course construction; also want to emphasize "learning" and "production", the combination of clear job prospects and development of Landscape Ecology to study direction, positive out of a law in line with the market economy and the path of practice teaching to promote. (4) Strengthen the construction of teaching staff. Including promoting teacher's professional level, strengthen the practical experience and professional training, and to establish a set of incentives, supervision and management mechanism of teacher evaluation.

The Thinking and Countermeasures of Teaching Reform of Landscape Ecology. The Construction of Course Knowledge System. The construction of Course knowledge system should be based on its own characteristics, and to focus on the needs of the development of the various professional to enrich the theory of Landscape Ecology and results. Curriculum system construction of Landscape Ecology principles should be paid attention to the following aspects: a. Clear the basic principles of the building of the curriculum knowledge system. Should follow the overall concept, basic and advanced, landscape space configuration description pattern and landscape function, the relationship between dynamic change, driving force of landscape evolution and landscape management inner link, and the combination of theory and practice, in particular to highlight the value of landscape multiple practice principles of . b. Emphasizes the commonality of curriculum. That regardless of which major should master the course content, such as according to the agriculture, forestry and agriculture, land resources management in colleges and universities, geographical science, forestry, and more focus on the characteristics of the ecological environment engineering, through the teaching of Landscape Ecology, forest, land, agriculture, people can be closely combined with the environment, it is in colleges and universities of all kinds of ecological environment of agriculture and forestry specialized training goal. c.Outstanding the characteristics of professional. The curriculum, in addition to the common, should also highlight the professional characteristics. The knowledge system of Landscape Ecology teaching should be based on the needs of different professional to adjust. For example, the direction of landscape architecture, landscape planning, and tourism management students, in addition to teach in teaching the application of Landscape Ecology basic theory, also should focus on strengthening landscape space portfolio model combining ecological effect and landscape planning study; Ecology majors at the same time, to grasp the basic theory and principle should focus on the research of landscape formation, the functional flow of space and time differentiation and classification of ecological planning and evaluation methods; Land resources management major and geographical science majors can be appropriately increased land cover changes, drive mechanism and ecological security pattern and warning the aspects of teaching content; Urban management major should pay attention to the aspects of tourism development and urban and rural planning application; Forestry professional pay more attention to sustainable development, regional planning, sustainable utilization of natural resources, etc. Department of ecology Landscape Ecology course teaching, for example, set up covering basic theory and principle of Landscape Ecology and landscape formation factors, landscape structure and spatial pattern, landscape ecological flow and function, landscape dynamic change, landscape ecological classification and evaluation of landscape ecological planning and landscape ecological quantification method and practice of Landscape Ecology (practice), and other aspects of knowledge structure system.

Practice Teaching Content Reform. The practice teaching reform is to strengthen the teaching of visual and participatory and stimulate students' intellectual potential and innovation consciousness, cultivate skilled and applied talents, including the following aspects: the content of the reform selection of practice content. In extensive reference to other related professional courses based on the practice teaching, combining with the professional training goal, content is very important to 
choose the appropriate teaching practice. Based on the characteristics of agriculture and forestry colleges and universities set up professional background and disciplines, to build a set of experimental models of the Landscape Ecology system and intuitive model as the main line, build a multi-level and operational, the professional characteristic practice teaching system, including the following landscape space and structure analysis, computer simulation and the increase of the operation skills and landscape planning and design skills overall evaluation module. Improve the field practice base construction. practice base is the material basis and fundamental guarantee to realize the practice teaching, only according to the requirement of the practice teaching, create a type is complete, function, reasonable structure of form a complete set of practical teaching base, to make innovation concept to implementation and implementation. Choice of Landscape Ecology practice base is usually to meet the following conditions: have special landscape features. Landscape is an organic entity, eventually formed by human perception of visual characteristics and ecological characteristics, such as patch, corridor, matrix model, various types of landscape, and a typical island effect, etc. complete ecological system. Only so can ensure that landscape structure and the function is perfect, and to study the relationship between landscape pattern and ecological process, landscape boundary number, length, fractal characteristics. To grasp the original information. Such as practice base of remote sensing images, aerial photo, topographic map, or landscape classification map and other geographic information and the social economic foundation data, etc. facilities, construction of laboratory construction and experimental teaching platform.

The Teaching Method Innovation. Landscape Ecology courses for many years in practice, the teaching method reform advocates earnestly to the classroom and after-school self-study in combination with phase method, case teaching, scene analysis method and fallacies, multimedia demonstration teaching method, the hot issue discussion method and so on the many kinds of teaching methods integration innovation, integrated use. change the traditional cramming method of teaching. Advocate free choice study, give full play to the subjective initiative, will "consider" textbook knowledge is internalized into their own knowledge, using the heuristic interactive teaching mode. Cultivate students' ability of independent thinking is good at forensics, Confucius said: "learning without thought is labor lost; thought without learning is perilous". Only combining learning with thought can achieve mastery through a comprehensive study, knowledge. to the case analysis to stimulate learning enthusiasm. For example, in the theory of island biogeography, is good at this, the concept of "island" derivative to fire left after cutting interference such as small piece of "forest island", surrounded by a desert "oasis", and so on. Through the multimedia teaching to strengthen the consciousness of intuitive. Used on a large number of teaching professor visual landscape photos, remote sensing image and drawing landscape space morphology; Corresponding to different space combination pattern, landscape effect and ecological effect of teaching; As illustrated, vivid images show the unique charm of landscape. try to network teaching and realize resources sharing. Recommendations will be excellent teaching video posted on the Internet, specialize in Landscape Ecology BBS, through the channel can make the teaching contents, methods, complement each other, learn from each other. Promote innovative learning. Encourage students to sign up for the bold innovation related to college students' innovative projects, innovative experiments and the challenge that can strengthen the communication between various disciplines, but also can cultivate students to explore, innovation, intelligence development, practical, team spirit, and many other qualities. 


\section{The Diversification of Teaching Pattern of the Landscape Design Research}

Landscape Design Course. Landscape design course of explicit teaching objects, teaching contents, diversified landscape design course should be based on their special properties will be located in the teaching goal of "knowledge structure diversification, diversification of actual combat skills training high quality, comprehensive landscape design class talent", only made clear the goal, to meet the needs of today's society to landscape design class talented person standard, at the same time, it puts forward higher requirements to the teaching content.

Landscape design is the integration of liberal arts and science, knowledge in range is relatively wide, including literature, history, geography, architecture, engineering, etc., and focused on the cross complementary knowledge. Because of this, on the premise of clear teaching goal, on the one hand, to further enrich the teaching contents in landscape design; On the other hand, should be fully coordinated various related disciplines fusion in the landscape design course The proportion of occupied with each other. for example, in the landscape design course should be fully embody botany, landscape design and landscape architecture, garden horticulture, the combination of related subjects such as history, literature, knowledge structure, at the same time the landscape design of the original algorithm, methods, steps and the elements of landscape design analysis and so on course content should be dominant, and the natural elements in the landscape design elements should be fully combined with geography, botany, landscape garden horticulture knowledge such as teaching, in the artificial elements in landscape design elements, should be fully combined with the teaching of knowledge of history, culture, architecture and so on.

Through the landscape design course teaching content is diverse patterns of way, make the concept of landscape design education towards its teaching goal step by step.

The Landscape Design Course Topic Selection Should Pay Attention to the Diversification of Teaching. Combined with social demand for landscape design talents standards and clear teaching goal, in the landscape design course teaching should adhere to the multi-level, multi-angle, from the overall to the diversity of specific teaching topic selection model.

Teaching topic selection should be based on the overall framework, the various types of landscape design subject in-depth, specifically, form the multi-level teaching topic selection model. Teaching topic, for example, square landscape design can be according to the different classification of square type separately; Strip of space landscape design teaching topics from road landscape design and shore water landscape design two aspects; Teaching subject of city park landscape design can be divided into comprehensive park landscape design, landscape design, children's park forest park landscape design, the botanical garden landscape design and landscape design in the zoo.

The Landscape Design Course of Diversified Teaching Method. In view of the present domestic are more traditional, relatively single "theory + design" teaching method, the landscape design teaching methods can be from "theory + practice + experiment and actual combat" diversified aspects simultaneously.

The Theory Teaching of Teaching Methods. Through the theoretical study to make the students to the general situation of landscape design both at home and abroad have a preliminary understanding. On the one hand, through the appreciation of good landscape design works at home and abroad, make the students to broaden their; On the other hand, causes the student to fully understand the connotation of landscape design and its social value, at the same time, a solid grasp of scientific and reasonable landscape design principles, methods, steps, etc. 
The Field Practice Teaching. Encourage and guide students to the field practice, landscape construction field make a combination of theory knowledge and practice in teaching, makes theoretical knowledge practice good guidance, but also make practice of theoretical knowledge digestion, absorption, the best way. In the process, make the students understand the formation process of good landscape and how it is gradually perfect and mature. As "people is the main part of the cognitive object, the object is the object of cognition, and cognition is the main body of the object in the scene gradually sublimation process of aesthetic and appreciation." at the same time, it is also fully respect the student in the teaching of cognitive structure of the teaching experiment.

Courses Experimental Teaching Method. Experiment is aimed at diversification of landscape design course topics, produce various types of landscape design model, in the process of making model for on-the-spot practice interlinked with true feelings, feelings, feelings of landscape environment in space scale of psychological demand, etc.

The Actual Teaching Practice. Through practical exercises, students will study landscape design course in the first three parts absorb by the integrated use of knowledge, strengthen students' understanding of the theoretical part and the theoretical knowledge in practice the ability to use flexibly, and stimulate students in the process on the basis of respect for local culture innovation thinking.

The Assessment Mode Diversification of Landscape Design Course. For some traditional subjects, the assessment methods of usually the adoption of a single way of theory or experiment of examination, to achieve comprehensive evaluation criteria of landscape design, the traditional curriculum evaluation methods have some shortcomings.

Landscape design is a practical stronger course, theory to guide practice, practice and promote the development of the theory. Therefore, students must be good at the same time the landscape design course theory accomplishment and strong ability of practical design, so the landscape design course appraisal to student's theoretical accomplishment, design production ability and practice ability of comprehensive assessment such as multiple directions. Examination of the specific ways to reference on the whole landscape case gave students a complete set of design, but specific to conduct a comprehensive investigation from the following three aspects:

Theoretical Examination. Asked the students according to their own design with a certain length limit of design specification (may limit the length limit of 3000 words or so), or to complete a course paper design. Through the theoretical part of the assessment, can a comprehensive and in-depth investigation plan for middle school students own design ideas and design concept.

The Production Ability of the Inspection. Asked the students according to their own design make landscape model according to certain proportion. In model can fully examining the students of space scale, scale coordination control ability and the landscape environment of artistic processing ability and so on. Should be reflected as real as possible model making landscape design content.

Design Scheme Evaluation. Students are required to make a certain level of a full set of landscape design, including the layout, traffic plan and landscape plant plan, construction drawing, rendering and a series of complete schemes, and bound into the text. Through the appraisal of design scheme can comprehensive investigation the student to the course learning result and performance ability of solution.

Landscape design of the curriculum evaluation in combining the above three evaluation at the same time, should also be determined according to the design to the difficulty of the questions by the students a single complete or group cooperation. In way of grading, considering actively encourage students comprehensive cultivation of his landscape design literacy in normal times, you 
can refer to the final assessment result as worth $60 \%$ of the usual performance scores account for $40 \%$ of the total grade. Through such score way, causes the student to weaken the traditional concept of one-sided attention to score in the exam, turned its attention to daily to the cultivation of their comprehensive design literacy, the purpose is to strengthen the establishment of the knowledge accumulation and encouraging innovative thinking mode.

\section{Conclusion}

After thinking of the teaching reform, the author put them into teaching practice and practice inspection of these ideas is effective, improve the students' professional skills. Due to the closer to the actual course content more concise, method of teaching students more easy to accept; Practice project combined with the multimedia teaching, and the case analysis, targeted follow the market development, cooperate with landscape practice, improved the students' learning enthusiasm, also added a employment channels. Of course, these measures still need to improve, the exploration of teaching reform will continue. At the same time, also make the cultivation of the students in a diverse landscape design course teaching pattern, landscape and landscape aesthetic appreciation ability to improve, eyes open, and ultimately create a good landscape design works with a strong taste of new era. This article from the current domestic exploration on the general situation of the teaching mode, the landscape design course, from the current domestic landscape design problems existing in the teaching of specific analysis, from establishing the diversified teaching pattern of the landscape design of a new intensive research, aims to explore a more suitable for social development needs, is more advantageous to develop students for landscape design of the innovative teaching mode of thinking, after training with comprehensive quality and practice ability of landscape design talent, and further promote China's landscape design industry and the development of landscape architecture education.

\section{References}

[1] Xiang Xiaoxiao. Environmental art professional teaching reform of landscape design study [J]. Journal of Nanchang Institute of Education. 2013 (4)

[2] liu Chun-bo . Analyses of landscape environmental art [J]. The Young Writer. 2010 (18)

[3] Zhang Qi-man, Pan Wuhua. Interior design data set 2 [M]. Beijing: China Building Industry Press. 1999

[4] Hong Yi-Min. Reform the teaching method [J] training innovative talents. Beijing: Chinese Journal of Women's College. 2008 (4)

[5] Pan Wu-hua. Indoor display art design. Beijing, China Building Industry Press, 1999 